\title{
PALAVRAS COMPOSTAS DO TIPO VERBO + SUBSTANTIVO EM GALEGO, COMPARAÇÃO COM O PORTUGUÊS \\ E O ESPANHOL
}

\section{VERB + NOUN COMPOUNDS IN GALICIAN, COMPARISON WITH PORTUGUESE AND SPANISH}

\author{
Ildikó Szijj ${ }^{1}$ \\ Universidade Eötvös Loránd de Budapeste
}

Resumo: O objetivo deste artigo é estudar o inventário das palavras compostas do tipo verbo + substantivo (p. ex. port. arranha-céus) no galego, no português e no espanhol para averiguar com qual das duas línguas o galego apresenta maior semelhança. Como corpus foram utilizados dicionários monolingues das três línguas. $\mathrm{O}$ resultado da pesquisa é que há mais casos de coincidência com o espanhol. Existem diferenças semânticas entre o grupo dos elementos que coincidem com o espanhol e os que coincidem com o português.

Palavras-chave: Palavras compostas verbo + substantivo; Inventário dos compostos; Coincidência e diferença entre o galego e o espanhol ou o português.

$1 \quad$ szijj.ildiko@btk.elte.hu 
Abstract: The aim of this paper is to study the inventory of verb + noun compounds (e.g. port. arranhacéus) of Galician, Portuguese and Spanish, in order to show with wich of the two languages Galician is more similar. The corpora were monolingual dictionaries of the three languages. The result of the investigation is that there are more cases of coincidence between Galician and Spanish. Semantical differences can be detected between the group of compounds that are similar in Galician and Spanish and those that are similar between Galician and Portuguese.

Keywords: Verb + noun compounds; Inventory of compounds; Coincidence and difference between Galician and Spanish or Portuguese.

\section{INTRODUÇÃO}

O objetivo deste artigo é apresentar uma série de palavras compostas em galego e verificar se estas mesmas palavras existem em português e em espanhol.

O galego começou a divergir do português no século XIV, e posteriormente viveu em contacto estreito com o espanhol. Por isso, tem uma forte ligação com ambas as línguas. Uma possível linha de pesquisa pode ser comparar com qual das duas tem hoje maior semelhança na pronúncia, na gramática, no léxico, na fraseologia, etc. O presente artigo pretende fazer uma comparação entre as palavras compostas do tipo verbo + substantivo, p. ex. port. quebra-nozes. Este tipo de composição vem do latim vulgar tardio (CÂMARA, 1985, p. 213; FERREIRO, 1997, p. 226), pelo que existiu desde a formação do galego-português e do espanhol, e continua a ser produtivo (VILELA, 1994, p. 92; CÂMARA, 1985, p. 214; LANG, 1992, p. 106).

Os compostos do tipo verbo + substantivo, como quebra-nozes, nascem pela reanálise de uma estrutura sintática, que é interpretada como uma palavra (VILLALVA, 2003, p. 982). São considerados normalmente como compostos de tipo exocêntrico (para uma interpretação diferente v. p. ex. VARELA, 1992, p. 110; comentários à interpretação de Varela em FÁBREGAS, 2013, p. 98-99). Compõem-se de uma forma verbal que pode ser analisada de diferentes maneiras (VAL ÁLVARO, 1999, p. 4789-4793; AGUIRRE, 2013, p. 186) e um 
substantivo geralmente inanimado, com função de objeto direto e papel temático de tema (VARELA, 1992, p. 113). O substantivo tem muitas vezes forma de plural. Raramente depois do verbo pode aparecer um adjetivo (p. ex. port. fala-barato) (VILLALVA, 2003, p. 983). Este modelo de composição tem preferência por certos verbos, p. ex. guardar (guarda-chuva, guarda-costas) (LANG, 1990, p. 108). O composto tem, geralmente, significado agentivo (p. ex. profissão, guarda-costas, também pode designar um animal ou uma planta, como beija-flor e girassol), instrumental (quebra-nozes) e em menos casos locativo (lava-louça) (VARELA, 1992, p. 109, VILELA, 1994, p. 92). Referido a uma pessoa, pode ter um valor pejorativo (fala-barato) (LANG, 1990, p. 108). O composto é de género masculino quando tem interpretação de instrumental (quebra-nozes), os nomes agentivos referentes a pessoas são comuns de dois (porta-voz) (VILLALVA, 2003, p. 983).

No caso de fazermos uma comparação entre o galego, o português e o espanhol, como primeira hipótese, parece natural que certas palavras compostas sejam comuns nas três línguas, porque noutras línguas também aparece um tipo de composição equivalente, p. ex. gal. rañaceos, port. arranhacéus, esp. rascacielos (inglês skyscraper, alemão Wolkenkrazer, húngaro felhókarcoló, etc.); gal. crebanoces / quebranoces, port. quebra-nozes, esp. cascanueces (inglês nutcracker, alemão Nussknacker, húngaro diótörő, etc.). Por outro lado, há objetos ou conceitos que, segundo as línguas, podem ser designados por palavras compostas, derivadas ou por um elemento léxico independente. Numa mesma língua pode haver também sinónimos de diferente tipo, e o uso dos sinónimos pode ter uma distribuição geográfica. P. ex. o instrumento que serve para afiar o lápis em português tem as denominações afia-lápis, apara-lápis, afia, afiador, aguça (Infopédia). Afia-lápis e para-lápis representam o mesmo tipo de composição, afia é um encurtamento da palavra composta, enquanto afiador é uma palavra derivada. A palavra $a g u c ̧ a$ é uma derivação regressiva de aguçar ou nasceu por 
apócope de aguçadeira (Infopédia). Podemos mencionar também um exemplo espanhol: a palavra composta rompehuelgas ('fura-greves') usa-se em vários países da América Latina, enquanto em Espanha se utiliza uma palavra simples, o catalanismo esquirol. Por isso, pode-se comparar se diferentes línguas escolhem o mesmo tipo de criação lexical. Noutros casos o significado da palavra composta é menos transparente, p. ex. a palavra portuguesa colibri tem os sinónimos beija-flor, chupa-flor, suga-flor (Infopédia). Pode ser interessante ver se estas palavras compostas existem também noutras línguas.

\section{METODOLOGIA}

Para fazer a comparação entre as línguas, como corpus, para o galego usei o dicionário da Real Academia Galega (RAG) e para o espanhol o dicionário da Real Academia Española, em ambos os casos a versão on-line. Para a comparação com o português o meu corpus foi o dicionário on-line Infopédia. Nalguns casos é possível que na língua (falada) exista uma palavra composta não documentada nos dicionários utilizados, que se pode encontrar noutras fontes ou na Internet, mas preferi limitar-me ao material léxico das fontes indicadas. P. ex. na gramática galega de Álvarez e Xove (2002, p. 737) aparecem as palavras gardamanteis ou tirarrollas, não documentadas no dicionário da RAG. Também é preciso sublinhar que o dicionário galego e o espanhol que usei são dicionários normativos. No caso do português, optei pela Infopédia, porque contém mais elementos do que o dicionário normativo da Academia (DLPC). P. ex. tive em conta palavras como mija-cão, pica-folha, picanariz, tapa-buraco, viravento, que não aparecem no DLPC, mas sim na Infopédia. Antes de usar a versão on-line do dicionário galego, fiz uma lista de palavras segundo o material léxico de dicionários em papel, a começar pelo dicionário da RAG (1997). O meu corpus final consiste de 121 palavras compostas galegas e os seus eventuais equivalentes em português e em espanhol. 
Apresento as palavras em 4 grupos: semelhança entre o galego e o português, entre o galego e o espanhol, semelhança entre as três línguas e solução particular do galego, sem paralelismo nas outras línguas. Enumero as palavras galegas por ordem alfabética. Ao lado aparece a palavra da outra língua com que apresenta semelhança. Entre parênteses dou de forma muito simplificada o significado, indicando brevemente se há qualquer diferença entre as línguas. Isto é, quando falo de semelhança, tenho em conta, em primeiro lugar, a forma da palavra.

Para dar um exemplo, no galego existe a palavra composta abrebocas, no português abre-boca, no espanhol abreboca. Considero que as palavras são semelhantes, mas enquanto a palavra galega e portuguesa significam 'instrumento que serve para abrir a boca', o significado da palavra espanhola é 'aperitivo'.

Por outro lado, também considero que há semelhança entre palavras como gal. rañaceos e esp. rascacielos, gal. gardalama e esp. guardabarros ou gal. sacamoas e port. tira-dentes. Nestes pares de palavras a forma do verbo, do substantivo ou dos dois elementos é diferente, mas os elementos são semanticamente equivalentes (gal. rañar e esp. rascar; gal. lama e esp. barro, gal. sacar e port. tirar, gal. moa e port. dente).

Mas não considero semelhantes p. ex. a palavra galega crebafolgas / quebrafolgas e a portuguesa fura-greves, porque o verbo furar não equivale a crebar / quebrar, isto é, a metáfora em que se baseia a palavra composta é diferente nas duas línguas.

Não incluo na minha lista palavras que não são realmente composicionais. P. ex. a palavra galega pasacalle é um empréstimo do espanhol, isto é, o substantivo calle não existe de forma independente no galego. Também não aparecem na minha lista palavras galegas que têm elementos que dificilmente poderiam aparecer numa das outras duas línguas, p. ex. gal. 
furabolos, furafrío, furafollas, porque o verbo furar não tem equivalente adequado em espanhol (horadar é um verbo pouco frequente, agujerear é um verbo derivado, como também o verbo anterior, e este tipo de verbos não aparece nos compostos).

\section{SEMELHANÇA ENTRE O GALEGO E O PORTUGUÊS}

Listo a seguir os compostos encontrados que apresentam semelhança formal nas línguas galega e portuguesa:

(1) gardacostas, port. guarda-costas ('pessoa que protege outra')

(2) lucecú, port. luze-cu (tipo de inseto)

(3) matabicho, port. mata-bicho (Em galego o significado da palavra é 'licor, principalmente aguardente, tomado em jejum', em português, significa também 'pequeno almoço'.)

(4) mexacán, port. mija-cão (tipo de planta) (Nome latino da planta designada pela palavra galega: Taraxanum officinale, nome da palavra portuguesa: Seneceo jacobaea. Segundo estes nomes latinos e as fotografias apresentadas pelo Google, não se trata da mesma planta. Uma vez que se trata de um problema específico da botânica, a partir daqui não vou comparar os tipos de plantas ou de animais designados por uma palavra comum nas línguas tratadas neste artigo.)

(5) paralama, port. para-lama(s) (Existe o sinónimo gardalama, que tem palavras correspondentes nas outras duas línguas: port. para-lama(s), esp. guardabarros. No entanto paralama só tem correspondente em português.)

(6) picafollas, port. pica-folha (Em galego a palavra designa um tipo de pássaro, em português um tipo de planta.)

(7) picanariz, port. pica-nariz (tipo de planta)

(8) picapau, port. pica-pau (A palavra galega designa um tipo de pássaro, a portuguesa tem este sentido e além disso designa um tipo de petisco e significa também 'espingarda antiga'.)

(9) picapeixe, port. pica-peixe (Em português a palavra significa um tipo de ave, como no galego, mas também um elemento náutico.)

(10) tapaburatos, port. tapa-buraco (A palavra galega significa 'filho mais novo', em português 'uma pessoa que desempenha uma função, na falta de outrem'. Em galego existe o sinónimo tapafurados.)

(11) vagalume, port. vaga-lume (tipo de inseto) 
(12) virachaquetas, port. vira-casaca ('pessoa que muda facilmente de opinião')

(13) viravento(s), port. vira-vento (A palavra galega designa um instrumento, a portuguesa pode designar um tipo de brinquedo.)

Entre as 13 palavras, 2 têm significados diferentes (palavras (6), (10)); as outras diferenças semânticas são parciais. As palavras portuguesas mija-cão, pica-folha, pica-nariz, tapa-buraco, vira-vento não aparecem no DLPC, isto é, não devem ser palavras muito frequentes. Das 13 palavras, 7 são nomes de plantas ou animais, 3 designam pessoas, 2 instrumentos, e o exemplo (3) tem um significado mais especial ('licor').

\section{SEMELHANÇA ENTRE O GALEGO E O ESPANHOL}

Na sequência, os compostos encontrados que apresentam semelhança formal nas línguas galega e espanhola:

(1) buscabullas, esp. buscabulla ('pessoa que provoca discórdia') (A palavra espanhola usa-se no México.)

(2) comemerda, esp. comemierda (A palavra galega designa um tipo de ave, a espanhola 'uma pessoa desprezável'.)

(3) cortaúnllas / cortaúñas, esp. cortaúñas (instrumento)

(4) crebafolgas / quebrafolgas, esp. rompehuelgas ('pessoa que não participa na greve', a palavra espanhola usa-se em vários países americanos)

(5) gardaagullas, esp. guardagujas ('empregado do caminho de ferro')

(6) gardacabos, esp. guardacabo ('anel metálico')

(7) mirasol, esp. mirasol (planta) (Em português usa-se pouco o verbo mirar, mas há outras palavras compostas e derivadas com esta palavra, p. ex. mira-olho, miradouro.)

(8) pasamáns, esp. pasamano (A palavra galega significa 'corrimão', a espanhola designa também uma parte do navio e tem outros significados no espanhol americano.)

(9) pelagatos, esp. pelagatos ('pessoa insignificante')

(10) portalámpada, esp. portalámpara ('parte da lâmpada') 
(11) portapapeis, esp. portapapeles (termo informático)

(12) repousabrazos, esp. reposabrazos ('peça dum móvel/no carro para os braços')

(13) repousacabezas, esp. reposacabezas ('peça dum móvel/no carro para a cabeça')

(14) sacabocados, esp. sacabocado(s) (A palavra espanhola além de designar um instrumento, como a palavra galega, tem também um sentido figurado.)

(15) tapacubos, esp. tapacubo(s) ('parte da roda')

(16) tapacús, esp. tapaculos (Em galego a palavra significa um tipo de peixe, em espanhol designa um fruto, e como dialetalismo tem ainda outros significados.)

(17) taparrabos, esp. taparrabos (peça de roupa)

(18) tapaxuntas, esp. tapajuntas (termo da construção)

(19) tirapedras / tiracroios, esp. tirapiedras (instrumento para atirar pedras, a palavra espanhola usa-se nalguns países da América)

(20) tiratacos, esp. tiratacos (significado parecido a tirapedras / tirapiedras)

Entre as 20 palavras, 2 têm significados diferentes (palavras (2), (16)). Entre as palavras há 3 nomes de plantas ou animais (pelo menos numa das línguas). As palavras designam, na maioria, instrumentos (p. ex. (3)), objetos com uma qualquer função (p. ex. (12)) ou uma pessoa (p. ex. (1)). As palavras que designam instrumentos ou objetos funcionais são transparentes do ponto de vista do significado.

\section{SEMELHANÇA ENTRE AS TRÊS LÍNGUAS}

Depois de cada uma das palavras seguintes, que apresentam semelhança formal nas três línguas, indico se há também semelhança entre os significados. Também tenho em conta se a semelhança é só parcial.

(1) abrebocas, port. abre-boca, esp. abreboca (A palavra galega e a portuguesa designam um instrumento, a espanhola significa 'aperitivo'.) significado: G-P

(2) abrecartas, port. abre-cartas, esp. abrecartas (instrumento) G-P-E

(3) abrelatas, port. abre-latas, esp. abrelatas (instrumento) G-P-E

(4) afialapis, port. afia-lápis, esp. afilalápices (instrumento) G-P-E 
(5) batecú, port. bate-cu, esp. baticulo ('queda de cu') G-P-E

(6) botafogo, port. bota-fogo, esp. botafuego (No português e no espanhol, além do sentido concreto de 'pau para acender uma arma', a palavra tem um sentido figurado, significando 'pessoa que provoca distúrbios'.) G-P-E

(7) buscavidas, port. busca-vidas, esp. buscavidas (A palavra galega significa 'pessoa que sabe resolver situações complicadas', a espanhola, além deste sentido, significa também 'pessoa curiosa', enquanto a palavra portuguesa designa diferentes tipos de instrumento.) G-E

(8) catavento(s), port. cata-vento, esp. cataviento (Há uma ligeira diferença no significado. A palavra galega designa um instrumento no telhado, e a espanhola e a portuguesa designam também um instrumento para determinar a direção do vento, num navio (palavra espanhola) ou num aeroporto (palavra portuguesa). A palavra portuguesa tem também um sentido figurado: 'pessoa volúvel'.) G-P-E

(9) chupamel / chuchamel, port. chupa-mel, esp. chupamiel (A palavra galega e a portuguesa designam um tipo de planta, e a espanhola usa-se nalguns países americanos e é sinónimo de colibri.) (Segundo o DLPC significa também 'colibri') G-P

(10) contagotas, port. conta-gotas, esp. cuenta-gotas (instrumento) G-P-E

(11) contaquilómetros, port. conta-quilómetros, esp. cuentakilómetros (instrumento) GP-E

(12) crebanoces / quebranoces, port. quebra-nozes, esp. cascanueces (A palavra designa nas três línguas um instrumento, e no português e no espanhol designa também um tipo de pássaro.) G-P-E

(13) fincapé, port. finca-pé, esp. hincapié (A palavra galega tem sentido figurado, e a portuguesa e a espanhola têm também sentido concreto.) G-P-E

(14) limpabotas, port. limpa-botas, esp. limpiabotas (pessoa) G-P-E

(15) limpachemineas, port. limpa-chaminés, esp. limpiachimeneas (A palavra galega e a espanhola designam a pessoa que tem o ofício indicado, e a palavra portuguesa designa também um instrumento.) G-P-E

(16) limpaparabrisas, port. limpa-para-brisas, esp. limpiaparabrisas (instrumento) GP-E

(17) gardabarreira, port. guarda-barreira, esp. guardabarrera (A palavra portuguesa significa também 'empregado aduaneiro', sendo que o significado de 'empregado dos caminhos de ferro' é comum nas três línguas.) G-P-E

(18) gardabrazo, port. guarda-braço, esp. guardabrazo ('parte da armadura') G-P-E

(19) gardacostas, port. guarda-costas, esp. guardacostas (tipo de barco, sendo que no significado de 'barco' há diferenças: no português é um 'navio de guerra', e nas outras duas línguas significa também um barco mais pequeno.) G-P-E

(20) gardafreos, port. guarda-freio, esp. guardafrenos (ofício) G-P-E 
(21) gardalama, port. guarda-lama(s), esp. guardabarros (O significado comum é uma parte dos veículos. A palavra portuguesa designa também uma parte do vestido.) G-P-E

(22) gardamán, port. guarda-mão, esp. guardamano ('parte da armadura', tendo em português também outros significados parecidos) G-P-E

(23) gardameta, port. guarda-meta, esp. guardameta ('guarda-redes') G-P-E

(24) gardamontes, port. guarda-mato, esp. guardamonte(s) (A palavra galega designa a pessoa que vigia o monte. A palavra espanhola guardamonte(s) significa a pessoa que guarda o monte (também guardabosque), e guardamonte designa uma parte das armas de fogo e um tipo de casaco. A portuguesa tem estes últimos significados.) G-E

(25) gardapó, port. guarda-pó, esp. guardapolvo(s) (A palavra galega designa um casaco, a portuguesa designa também uma peça do telhado, e a espanhola tem ainda outros significados, p. ex. designa uma parte do relógio.) G-P-E

(26) gardarríos, port. guarda-rios, esp. guardarrío (A palavra galega designa a pessoa que vigia o rio, e a espanhola designa um tipo de pássaro. A palavra portuguesa tem os dois significados.) G-P

(27) gardarroupa, port. guarda-roupa, esp. guardarropa (Nas três línguas designa um armário, um quarto, o conjunto de peças de vestir ou uma pessoa.) G-P-E

(28) lambecús, port. lambe-cu, esp. lameculos (pessoa) G-P-E

(29) lanzachamas, port. lança-chamas, esp. lanzallamas (arma) G-P-E

(30) marcapasos, port. marca-passos, esp. marcapasos (dispositivo) G-P-E

(31) matapiollos, port. mata-piolhos, esp. matapiojo/matapiojos (A palavra galega e a portuguesa designam o dedo polegar. A palavra espanhola matapiojo usa-se no México e noutros países americanos e designa um tipo de árvore, e matapiojos usa-se no Chile e na Colômbia e significa 'libélula'.) G-P

(32) matapulgas, port. mata-pulgas, esp. matapulgas (A palavra galega e a espanhola designam uma planta, e a palavra portuguesa é sinónimo de mata-piolhos, significando 'dedo polegar'.) G-E

(33) matarratos, port. mata-ratos, esp. matarratón (palavra galega: 'veneno', 'comida ou bebida de má qualidade', palavra portuguesa: 'veneno', 'vinho de má qualidade', a palavra espanhola matarratón designa uma planta nalguns países americanos, e matarratas significa 'veneno' e 'aguardente de má qualidade'.) G-PE

(34) papamoscas, port. papa-moscas, esp. papamoscas (A palavra galega e a espanhola designam um tipo de pássaro e uma pessoa ingénua, e a portuguesa também uma planta.) G-P-E

(35) parabrisas, port. para-brisa, esp. parabrisa(s) (parte do carro) G-P-E

(36) paracaídas, port. para-quedas, esp. paracaídas (instrumento) G-P-E 
(37) parachoques, port. para-choque(s), esp. parachoques (O significado comum é uma parte do carro. A palavra portuguesa indica também outros dispositivos e no calão 'seios da mulher'.) G-P-E

(38) pararraios, port. para-raios, esp. pararrayo(s) (A palavra nas três línguas designa um instrumento, e em português tem também sentido figurado.) G-P-E

(39) parasol, port. para-sol, esp. parasol (O significado comum é 'guarda-sol', e em português designa também um tipo de cogumelo.) G-P-E

(40) paraugas, port. para-águas, esp. paraguas (A palavra galega e portuguesa significam 'guarda-chuva', e a espanhola tem ainda outros significados.) G-P-E

(41) pasamontañas, port. passa-montanhas, esp. pasamontañas (gorro) G-P-E

(42) pasatempo, port. passatempo, esp. pasatiempo ('diversão') G-P-E

(43) portaavións, port. porta-aviões, esp. portaaviones / portaviones (navio de guerra) G-P-E

(44) portabandeira, port. porta-bandeira, esp. portabandera (No galego designa a pessoa e o objeto, no português só a pessoa, no espanhol o objeto e, no espanhol do México, a pessoa.) G-P-E

(45) portaenxertos, port. porta-enxerto, esp. portainjerto (planta) G-P-E

(46) portaestandarte, port. porta-estandarte, esp. portaestandarte (pessoa) G-P-E

(47) portafolios, port. porta-fólios / portafólio, esp. portafolio(s) (Além do significado comum de 'pasta', em português designa também os documentos.) G-P-E

(48) portahelicópteros, port. porta-helicópteros, esp. portahelicópteros (navio) G-P-E

(49) portalapis, port. porta-lápis, esp. portalápices (A palavra portuguesa tem também o significado de 'estojo'.) G-P-E

(50) portamoedas, port. porta-moedas, esp. portamonedas (objeto) G-P-E

(51) portavoz, port. porta-voz, esp. portavoz (A palavra galega designa uma pessoa ou meio de comunicação, e a palavra portuguesa e a espanhola, além disso, significam 'megafone'.) G-P-E

(52) quebracabezas / crebacabezas, quebra-cabeças, esp. rompecabezas (Além dos significados comuns de 'problema' e 'jogo', a palavra espanhola designa também uma arma.) G-P-E

(53) quebraxeos / crebaxeos, port. quebra-gelos, esp. rompehielos (tipo de embarcação) G-P-E

(54) a queimarroupa, port. a queima-roupa, esp. a quemarropa (de perto) G-P-E

(55) quitamanchas, port. tira-nódoas, esp. quitamanchas (A palavra galega e a portuguesa designam o produto, e a espanhola o produto e a pessoa.) G-P-E

(56) rañaceos, port. arranha-céu(s), esp. rascacielos (edifício) G-P-E

(57) repousapés, port. repousa-pés, esp. resposapiés (peça para repousar os pés) G-PE 
(58) sacamoas, port. tira-dentes, esp. sacamuelas (A palavra tem o significado de 'dentista' nas três línguas, e no espanhol a palavra significa também 'pessoa que fala muito'.) G-P-E

(59) sacarrollas, port. saca-rolhas, esp. sacacorchos (instrumento) G-P-E

(60) salvavidas, port. salva-vidas, esp. salvavidas (A palavra galega é sinónimo de flotador, e a palavra espanhola salvavidas tem também outros significados, alguns só na variedade americana, na qual a palavra salvavida designa uma pessoa. A palavra portuguesa designa também um objeto e uma pessoa.) G-P-E

(61) tapabocas, port. tapa-bocas, esp. tapabocas (A palavra galega significa 'cachecol', a espanhola tem também outros significados, p. ex. 'pancada' ou 'máscara' nalguns países americanos, e a portuguesa significa 'pancada' e 'máscara'.) G-E

(62) tiraleite, port. tira-leite, esp. sacaleches (instrumento) G-P-E

(63) tiralinas, port. tira-linhas, esp. tiralíneas (instrumento) G-P-E

(64) tirapé, port. tira-pé, esp. tirapié ('correia') G-P-E

(65) tocadiscos, port. toca-discos, esp. tocadiscos (A palavra portuguesa usa-se no Brasil.) G-P-E

(66) tornasol, port. tornassol, esp. tornasol (planta; a palavra espanhola tem também outros significados) G-P-E

(67) trabalinguas, port. trava-língua, esp. trabalenguas (frase difícil de pronunciar) G-P-E

(68) xirasol, port. girassol, esp. girasol (Além de ser o nome duma planta, no português e no espanhol, a palavra designa também um tipo de mineral, além do significado comum de 'tipo de planta'.) G-P-E

Nesta longa lista a maior parte das palavras designam um objeto com certa função. Só há 2 palavras que designam a mesma planta nas 3 línguas, e são sinónimos (gal. tornasol, xirasol), e 3 outros nomes de plantas ou animais em galego. Em 4 casos há diferença semântica entre o galego e o português (palavras (1), (9), (26), (31)), e em 4 casos entre o galego e o espanhol (palavras (7), (24), (32), (61)). 


\section{PALAVRAS COMPOSTAS PECULIARES DO GALEGO}

Finalmente, os compostos encontrados que se mostram peculiares à língua galega:

(1) aguzalapis (instrumento)

(2) andacamiños (brinquedo)

(3) apañabolboretas (instrumento)

(4) apertarrabos ('situação difícil')

(5) catasol ('girassol', 'guardasol', tipo de tecido)

(6) comecartos ('coisa cara', máquina)

(7) escornabois ('vaca-loura')

(8) gardadedo (parte duma ferramenta)

(9) picacardos (tipo de pássaro)

(10) portacedés (instrumento)

(11) portavultos (parte do veículo)

(12) tapaconas (tipo de peixe)

(13) tapafurados ('filho mais novo')

(14) tiragrampas ('extrator de grampos'; no dicionário espanhol não aparece, mas no Google a palavra quitagrapas tem 863.000 ocorrências.)

(15) tornarratos (parte do hórreo)

Quatro das palavras designam animais ou plantas. Na lista há também palavras modernas (portacedés, tiragrampas), que, porém, não existem nas outras duas línguas ou não se documentam nos dicionários.

\section{DIFICULDADES NA ANÁLISE DAS CORRESPONDÊNCIAS}

Antes de resumir os resultados devo mencionar algumas dificuldades metodológicas. 
Considerei como semelhanças os casos em que encontrei as palavras nos dicionários utilizados. Mas em certos casos a palavra só é usada em certas variedades, p. ex. no português do Brasil ou no espanhol falado em certos países da América Latina. P. ex. toca-discos é usado no português do Brasil, enquanto no português europeu a palavra normal é gira-discos. A palavra espanhola tirapiedras é usada em Cuba e na República Dominicana, mas em Espanha usa-se tirachinas. Nestes casos, apesar da existência das palavras limitada a certas variedades diatópicas, considero que há semelhança entre as línguas. Noutros casos uma palavra tem uma aceção geral e outra limitada a certas variedades, p. ex. a palavra espanhola salvavidas tem significados como 'barco insubmersível' ou 'dispositivo dos elétricos', mas em Cuba e no Uruguai significa também 'gordura na cintura'.

Não tive em conta a frequência de uso das palavras, pois o meu critério foi a presença da palavra no dicionário. P. ex. no dicionário aparece a palavra espanhola limpiachimeneas, palavra composta que nos interessa neste artigo, mas paralelamente existe o sinónimo deshollinador. Esta última palavra tem 357.000 ocorrências no Google, enquanto limpiachimeneas aparece só 14.000 vezes. Nas outras duas línguas a palavra composta não tem outro sinónimo, ou seja, tem um uso mais extenso. Outro exemplo pode ser a palavra para-águas do português, que aparece no dicionário, embora as palavras mais usadas para designar o objeto em questão sejam guarda-chuva ou chapéu de chuva.

\section{CONSIDERAÇÕES FINAIS}

Comparando os compostos verbo + substantivo entre o galego, o português e o espanhol, as correspondências mostram maior semelhança entre as palavras compostas do galego e do espanhol (20) do que entre o galego e o 
português (13). No entanto, no maior número de casos coincidem as três línguas (68). E há poucas palavras especiais para o galego (15).

Para simplificar distingui três categorias principais no significado: planta/animal, objeto com alguma função, pessoa (pode ser uma profissão ou uma característica). A distribuição das palavras galegas seria a seguinte: planta/animal: 19, objeto com alguma função: 71, pessoa: 21. Algumas palavras ficam fora das três categorias, p. ex. gal. pasatempo, apertarrabos, etc. Ao mesmo tempo, algumas palavras pertencem a duas categorias, p. ex. gal. catasol, portabandeira.

Observando as correspondências com as outras duas línguas, estas três categorias semânticas têm a seguinte distribuição: semelhança galegoportuguês: planta/animal 7, objeto 3, pessoa 3; semelhança galego-espanhol: planta/animal 3, objeto 13, pessoa 4; semelhança entre as três línguas: planta/animal 5, objeto 46, pessoa 13; galego: planta/animal 4, objeto 9, pessoa 1. (Para dar estes números não tive em conta as discrepâncias entre os significados, só a categoria semântica da palavra galega.) Parece que os nomes de plantas e animais são proporcionalmente frequentes entre os casos quando a palavra coincide com a portuguesa, provavelmente porque são nomes tradicionais, antigos, que mostram o contacto secular das duas línguas.

Considerando que há um número elevado de palavras comuns nas três línguas, seria interessante fazer também uma comparação com outras línguas românicas, desde uma perspetiva onomasiológica, para observar se entre as três línguas estudadas há maior semelhança do que entre outras línguas da família românica.

\section{REFERÊNCIAS}

AGUIRRE, Carmen. Manual de morfología. Barcelona: Castalia, 2013. 
ACADEMIA DAS CIÊNCIAS DE LISBOA. Dicionário da Língua Portuguesa Contemporânea (DLPC). Lisboa: Verbo, 2001.

ÁLVAREZ, Rosario; XOVE, Xosé. Gramática da lingua galega. Vigo: Galaxia, 2002

CÂMARA Jr., Joaquim Mattoso. História e estrutura da língua portuguesa. Rio de Janeiro: Padrão, 1985.

FÁBREGAS, Antonio. La morfología. Madrid: Síntesis, 2013.

FERREIRO, Manuel. Gramática histórica galega: Volume II. Lexicoloxía. Santiago de Compostela: Laiovento, 1997.

LANG, Mervyn F. Formación de palabras en español. Madrid: Cátedra, 1992.

PORTO EDITORA. Infopédia. Disponível em: [https://www.infopedia.pt/dicionarios]. Acesso em: 09 jan. 2021.

REAL ACADEMIA ESPAÑOLA; ASOCIACIÓN DE ACADEMIAS DE LA LENGUA ESPAÑOLA. Diccionario de la lengua española. Disponível em: [https://academia.gal/dicionario]. Acesso em: 09 jan. 2021.

REAL ACADEMIA GALEGA. Dicionario da Real Academia Galega. Disponível em: [https://dle.rae.es]. Acesso em: 09 jan. 2021.

REAL ACADEMIA GALEGA. Diccionario da Real Academia Galega. A Coruña, 1997.

VAL ÁLVARO, José Francisco. La composición. In: BOSQUE, Ignacio; DEMONTE, Violeta. Gramática descriptiva de la lengua española. Madrid: Espasa, 1999. p. 4757-4841.

VARELA ORTEGA, Soledad. Fundamentos de morfología. Madrid: Síntesis, 1992.

VILLALVA, Alina. Formação de palavras: composição. In: MATEUS, Maria Helena Mira; BRITO, Ana Maria; DUARTE, Inês; FARIA, Isabel Hub. Gramática da Língua Portuguesa. Lisboa: Caminho, 2003. p. 969-983.

VILELA, Mário. Estudos de Lexicologia do Português. Coimbra: Almedina, 1994.

Nota do editor:

Artigo submetido para avaliação em: 09 de janeiro de 2021.

Aprovado em sistema duplo cego em: 18 de maio de 2021. 